\title{
BMJ Open Role of socioeconomic status and housing conditions in geriatric depression in rural China: a cross- sectional study
}

\author{
Mingwang Fang, ${ }^{1}$ Gebremeskel Mirutse, ${ }^{1}$ Ling Guo, ${ }^{2}$ Xiao Ma ${ }^{1}$
}

To cite: Fang M, Mirutse G, Guo L, et al. Role of socioeconomic status and housing conditions in geriatric depression in rural China: a cross-sectional study. BMJ Open 2019;9:e024046. doi:10.1136/ bmjopen-2018-024046

- Prepublication history for this paper is available online. To view these files, please visit the journal online (http://dx.doi. org/10.1136/bmjopen-2018024046).

Received 8 May 2018 Revised 24 December 2018 Accepted 4 January 2019
Check for updates

(C) Author(s) (or their employer(s)) 2019. Re-use permitted under CC BY-NC. No commercial re-use. See rights and permissions. Published by BMJ.

${ }^{1}$ West China School of Public Health, Sichuan University, Chengdu, China

${ }^{2}$ Department of Health

Management, Chongqing

Nursing Vocational College,

Chongqing, China

Correspondence to

Professor Xiao Ma;

antiaids@163.com

\section{ABSTRACT}

Objectives The primary aim of this study was to describe the socioeconomic status (SES), housing conditions and depression of the elderly in rural China, as well as to examine the associations between depression and SES and housing conditions using the China Health and Retirement Longitudinal Study (CHARLS).

Design This is a cross-sectional study.

Setting A nationally representative sample of elderly in rural China.

Participants A total of 4585 elderly adults in 2015 in rural China.

Outcome measures Prevalence and risk factors of depression among rural elderly.

Results Among the participants in this study, approximately $46.15 \%(2116 / 4585)$ reported depressive symptoms (10-item Center for Epidemiologic Studies Depression Scale [CESD-10] score $>10$ ) in rural China. The results revealed significant associations between higher scores on CESD-10 (indicating more symptoms of depression) and lowest personal annual income $(0 \mathrm{R}=1.63$, $95 \% \mathrm{Cl} 1.290$ to 2.060$)$, polluting cooking fuel $(\mathrm{OR}=1.16$, $95 \% \mathrm{Cl} 1.018$ to 1.321$)$, toilet without seat $(\mathrm{OR}=1.273$, $95 \% \mathrm{Cl} 1.056$ to 1.535 ), as well as having no bath facility $(\mathrm{OR}=1.172,95 \% \mathrm{Cl} 1.025$ to 1.341$)$ after adjustment for confounders.

Conclusion Elderly in rural China experienced severe depressive symptoms. Lowest personal annual income, polluting cooking fuel, toilet without seat and having no bath facility were significantly associated with more depressive symptoms. Caution needs to be taken in generalising the findings of this study to the rest of the population in China since its highly selected sample.

\section{INTRODUCTION}

Ageing is one of the most conspicuous phenomena in the contemporary world. Between 2015 and 2050, the proportion of the world's older adults is estimated to almost double from about $12 \%$ to $22 \%$. In absolute terms, this is an expected increase from 900 million to 2 billion people over the age of $60 .^{2}$ While population ageing is a global phenomenon, the progress is fastest in low-income and middle-income countries,

\section{Strengths and limitations of this study}

This study, which is based on a nationally representative data in China, contributes to implementation of cross-country comparisons and to collection of much more information about the effect of socioeconomic status and housing conditions on depressive symptoms.

- The main limitations are a cross-sectional study design and the use of self-reports.

- There were no further clinical diagnosis and treatments for the participants, who met the screening criteria according to the 10 -item Center for Epidemiologic Studies Depression Scale, in the original research.

especially in China. In 2016, the Chinese population aged above 60 years old was over 230 million, which will further increase to 480 million by $2050 .{ }^{3}$

Older adults face special physical and mental health challenges that need to be recognised. According to a WHO report published in 2017 , over $20 \%$ of the older adults suffered from the mental or neurological disorder (excluding headache disorders), and $6.6 \%$ of all disabilities among people over 60 years were attributed to mental and neurological disorders. Depression, one of the most common mental and neurological disorders, affects approximately $7 \%$ of the world's older population and comprises a substantial proportion of the global burden of disease. Depression among the Chinese older population first captured the research attention in the 1980s and emerged as a growing concern since the 1990s. ${ }^{4}$

Depression in the elderly is often a function of many contributing factors, which include biological, psychosocial or environmental characteristics. Socioeconomic status (SES), an important indicator of social structures, has consistently been found to be associated 
with geriatric depression. Some previous studies have shown that poor SES is related to the decrease in the ability to manage stress and further reduces the ability to deal with negative emotions and cognitions. ${ }^{5-8}$

Housing conditions are an important social determinant of health, and their association with the development of depressive symptoms is well documented in the literature. ${ }^{9-11}$ Housing conditions may encompass tangible and observable attributes, such as physical structure, design and housing facility. The association between housing conditions has been investigated in several studies, particularly in urban areas. ${ }^{12}$ Some previous studies have shown the relationship between mental health and different aspects of urban housing conditions. ${ }^{13-15}$ However, research on housing conditions and depression among rural populations is remarkably underdeveloped. Few studies have discussed in more detail the impact of rural housing conditions on depressive symptoms among the elderly, especially in China. ${ }^{16}$ In rural China, the poor physical housing conditions may lead to a greater possibility of depressive symptoms. With development and urbanisation, it is necessary to further focus on the relationship between rural housing conditions and mental health, which have a significant effect on the construction of age-friendly environments and further reduce the health inequality between urban and rural populations.

It is important to identify factors associated with depression in the rural population. Therefore, the primary aim of this study was to describe SES, housing conditions and depression in this population, as well as to examine the associations between depression and SES and housing conditions. We believe our study will improve understanding of the complex nature of the relationship between SES, housing conditions and the developing of depressive symptoms among the rural elderly population in low-income and middle-income countries.

\section{MATERIALS AND METHODS \\ Study design}

A cross-sectional design was used. The data were based on the third wave of the nationally representative China Health and Retirement Longitudinal Study (CHARLS) in 2015.

\section{Setting and participants}

CHARLS used a multi-stage stratified probability-proportional-to-size sampling technique to select participants. Face-to-face interviews were conducted to collect detailed information on participants. A total of 21095 respondents of 150 counties/districts and 450 villages/resident committees participated during the third wave in 2015. A more detailed CHARLS survey design has been described elsewhere. ${ }^{18-20}$

The sample included only adults aged 60 and above who lived in rural China. The inclusion criteria were (1) age $\geq 60$, (2) living at the survey site for at least 6 months, (3) being at home during the investigation period and
(4) ability to participate in the study. Subjects with mental retardation and severe cognitive impairment had been excluded from the original research by using a short screening form. Thus, the number of respondents eligible for our analysis dropped to 4585 rural elderly.

\section{Assessment and measurements}

\section{Depressive symptoms}

Depressive symptoms were screened by the 10-item Center for Epidemiologic Studies Depression Scale (CESD-10) short form. The time frame for the CESD-10 questions refers to the week prior to the interview. Each item was rated on a four-point Likert scale, with answers varying from 'rarely or none of the time (0-1 day)' to 'most or all of the time (5-7 days)'; the total score ranges from 0 to 30 , with a lower score indicating a lower level of depressive symptoms. CESD-10 has shown good validity and reliability in the Chinese population. ${ }^{21}$ A previous validation study found that a cut-off point of 10 had reasonable levels of sensitivity and specificity in Chinese older adults. Hence, a cut-off point of 10 was used in this study to generate the binary depressive symptom variable. Those participants with total scores of more than 10 were categorised as depressed. The CESD-10 has been described in detail elsewhere. $^{18}$

\section{Housing conditions}

Five variables were used to measure housing conditions: years of house building; housing structure; housing materials were dichotomized as 'improved material' (concrete and steel/bricks and wood) and 'unimproved material' (adobe, wood, cave dwelling, Mongolian yurt/wool felt and stone); number of bedrooms; cooking fuel (clean fuel/polluting fuel/others); and housing facility (availability of toilet, running water, shower or bath facility, heating system, telephone connection and Internet connection). These facilities were all categorised as ' $0=y e s$ ' (available) and ' $1=$ no' (unavailable), while toilet was categorised as ' $0=$ toilet with seat' and ' $1=$ toilet without seat'.

\section{Number of non-communicable diseases}

Non-communicable diseases (NCDs) were assessed as the cumulative number of diagnosed chronic conditions (hypertension; dyslipidaemia; diabetes; cancer; chronic lung diseases; liver or gallbladder disease; heart disease; stroke; kidney disease; stomach or other digestive diseases; emotional, nervous, or psychiatric problems; memory-related disease; rheumatism/arthritis; and asthma) that includes information collected from the clinical records available with the participants. They were categorised as ' 0 ', ' $1-2$ ' and ' 3 and above'. 0 was defined as participants who had no diagnosed chronic conditions. ${ }^{18}$

\section{Disabilities status}

It was measured by asking 'Do you have one of the following disabilities?' Responders were categorised as 'yes' when they had any disability or physical disabilities, brain damage/mental retardation, vision problem, hearing problem and speech impediment. 
Activities of daily living

Activities of daily living (ADL) limitations indicate any self-reported difficulty in any of the following six ADLs: eating, dressing, getting into or out of bed, using the toilet, bathing/showering, or controlling urination and defecation. The four response options were $1=$ 'I don't have any difficulty', 2 = 'I have difficulty but can still do it', $3=$ 'I have difficulty and need help' and $4=$ 'I cannot do it'. It was dichotomously coded (dependent vs independent). 'ADL dependent' was defined as 'have difficulty and need help' or 'cannot do it' in any ADL item.

\section{Socioeconomic status}

Education level and personal annual income were used to determine SES. Education level was classified as 'primary school and below' and 'high school and above'. Personal annual income (chinese yuan $[\mathrm{CNY}]$ ) was categorised as ' $\leq 10000$ ', ' $10000-20000$ ' and ' $\geq 20000$ '.

\section{Sociodemographic characteristics}

The sociodemographic variables considered in the analysis were age (60-69, 70-79, 80-89 and $\geq 90$ years), gender (male/female) and marital status (married or unmarried).

\section{Patient and public involvement}

The study did not involve patients. The results of the survey are disseminated to the public through websites of the public county councils.

\section{Statistical analysis}

All statistical analyses were conducted with SPSS (Statistical Package for the Social Science) V.22 for Windows. Data are presented with percentages and proportions for categorical values. The Pearson $\chi^{2}$ test was applied for categorical data to access statistical differences between groups. Binary logistic regression analysis was used to identify the potential risk factors of depressive symptoms. Ordered logistic regression was used to examine the relationship between SES, housing conditions and depression. Then the adjusted covariates, including age, gender, marital status, number of NCDs, disability and ADL, were added. Finally, four ordered logistic regression models were established.

\section{Results}

\section{Demographic characteristics}

Of the 4585 rural participants (2529 men and 2056 women), 3008 (65.61\%) were married and 1577 (34.39\%) were unmarried elderly. The participants ranged in age from 60 to 102 years (mean 69.46 \pm 7.34 ), with 59.15\% between the ages 60 and 69 . More than $4333(90 \%)$ were primary school and below, nearly four-fifths $(79.45 \%)$ had lowest personal annual income, nearly three-fifths (2615) had 2 kinds of chronic diseases. Among the participants in this study, approximately $46.15 \%(2,116 / 4,585)$ reported significant depressed (CESD-10 score $>10$ ) in rural China (table 1).
Demographic factors associated with depression: univariate findings

A univariable analysis revealed that eight demographic variables are associated with depression using $\chi^{2}$ tests at a significance level of 0.05 (table 1). Compared with those without depressive symptoms, participants with depression symptoms had a lower education level and personal annual income, had a worse health status $(57.61 \%$ older had one to two NCDs and $55.58 \%$ had disabilities) except for ADL limitation, in which only $19.90 \%$ were dependent. The percentage of married participants who experience depression was significantly higher than that of unmarried participants. $\chi^{2}$ tests revealed that age, gender, marital status, education level, number of NCDs, disability status and ADL limitations all had significant associations with depressive symptoms.

Housing conditions associated with depression: univariate findings Table 2 lists the frequency distributions of the housing condition variables across the outcome variable (depressive symptoms). It is particularly striking that $59.40 \%$ and $88.99 \%$ of the responders, who were depressed, reported using polluting cooking fuel and toilet without seat, respectively. $\chi^{2}$ tests revealed that housing materials, cooking fuel, type of toilet, running water, shower or bath facility had significant differences in depressive symptoms. In addition, other housing condition variables, such as the age of the house, housing structure, indoor temperature, number of bedrooms and heating system, were also analysed while these variables all had no significant difference among different depressive symptoms.

Binary logistic regression analysis of depressive symptoms: $0 \mathrm{R}$ $(95 \% \mathrm{Cl})$

The results of the binary logistic regression analysis of the associations between SES, housing conditions and depressive symptoms are shown in table 3. Model 1 included only controlled variables, including sociodemographic and health status factors, as a baseline model. In model 2, SES variables (marital status, education and income) were added to model 1 to explore the association between SES and depressive symptoms separately. In model 3, housing condition variables were added to model 1 to explore the impact of housing conditions on depressive symptoms separately. Model 4 added housing conditions and SES variables to model 1 to explain the impact of SES and housing conditions on depressive symptoms after controlling other variables.

The final regression model (model 4) showed that personal annual income, cooking fuel, type of toilet and bath facility were significantly and independently associated with depression. However, depression had no significant association with education and other housing conditions variables. Elderly participants with the lowest personal annual income $(\leq 10000)$ were 1.6 times more likely to have depression compared with participants with the highest personal annual income $(\geq 20000)$ $(\mathrm{OR}=1.63,95 \%$ CI 1.290 to 2.060). Older individuals who 
Table 1 Bivariate association between depressive symptoms and socio-demographic characteristics, SES and health status

\begin{tabular}{|c|c|c|c|c|}
\hline \multirow[b]{2}{*}{ Variable } & \multirow[b]{2}{*}{$\begin{array}{l}\text { Total } \\
\text { N (\%) }\end{array}$} & \multicolumn{2}{|c|}{ Depressive symptoms } & \multirow[b]{2}{*}{$\mathrm{P}$ value } \\
\hline & & $\begin{array}{l}\text { Not depressed } \\
\text { n (\%) }\end{array}$ & $\begin{array}{l}\text { Depressed } \\
\text { n (\%) }\end{array}$ & \\
\hline \multicolumn{5}{|l|}{ Age (years) } \\
\hline $60-69$ & $2712(59.15)$ & $1539(62.33)$ & $1173(55.43)$ & $<0.001$ \\
\hline $70-79$ & $1350(29.44)$ & $711(28.80)$ & $639(30.20)$ & \\
\hline $80-89$ & $476(10.38)$ & $205(8.30)$ & $271(12.81)$ & \\
\hline \multicolumn{5}{|l|}{ Gender } \\
\hline Male & $2529(55.16)$ & $1530(61.97)$ & $999(47.21)$ & $<0.001$ \\
\hline Female & $2056(44.84)$ & 939 (38.03) & $1117(52.79)$ & \\
\hline \multicolumn{5}{|l|}{ Marital status } \\
\hline High school and above & $252(5.50)$ & $160(6.48)$ & $92(4.35)$ & \\
\hline \multicolumn{5}{|l|}{ Personal annual income } \\
\hline$\leq 10000$ & $3643(79.45)$ & $1871(75.78)$ & 1772 (83.74) & $<0.001$ \\
\hline $10000-20000$ & $556(12.13)$ & $334(13.53)$ & $222(10.49)$ & \\
\hline$\geq 20000$ & $386(8.42)$ & 264 (10.69) & $122(5.77)$ & \\
\hline \multicolumn{5}{|l|}{ Number of NCDs } \\
\hline 0 & $698(15.22)$ & $458(18.55)$ & $240(11.34)$ & $<0.001$ \\
\hline $1-2$ & $2615(57.03)$ & $1396(56.54)$ & $1219(57.61)$ & \\
\hline$\geq 3$ & $1272(27.74)$ & $615(24.91)$ & $657(31.05)$ & \\
\hline
\end{tabular}

ADL, activity of daily living; NCD, non-communicable disease; SES, socioeconomic status.

used polluting cooking fuel were nearly 1.2 times more likely to have depression than those used clean cooking fuel (OR=1.16, 95\% CI 1.018 to 1.321). Older individuals who used the toilet without seat and had no bath facility were almost 1.3 and 1.2 times separately, more likely to have depression than those who used the toilet with seat $(\mathrm{OR}=1.273,95 \% \mathrm{CI} 1.056$ to 1.535$)$ and had a bath facility $(\mathrm{OR}=1.172,95 \%$ CI 1.025 to 1.341$)$ (table 3$)$.

\section{DISCUSSION}

\section{Key findings}

This study examined the association between SES, housing conditions and depressive symptoms in rural China. Among the participants in this article, approximately $46.15 \%(2116 / 4585)$ reported significant depression (CESD-10 score $>10$ ) in rural China, which was consistent with previous population-based surveys in China that found up to $44.2 \%$ of rural-dwelling older adults have depression and depressive symptoms. ${ }^{18} 21$

\section{SES and depression}

Using education level and personal annual income as measures of SES, we found that education level was not associated with depressive symptoms as other studies have found. ${ }^{18}$ Personal annual income was found to be a stronger factor in this study, and elderly participants with the lowest personal annual income $(\leq 10000)$ were 1.6 times more likely to have depression than participants with the highest personal annual income $(\geq 20000)$. Depressive symptoms among the elderly in rural China are positively related to better SES, in particular, personal annual income. This result is consistent with what other studies in China have found for depression, but is now replicated on a national sample and for the elderly population. ${ }^{21}$ Further, it has been suggested that poor SES may 
Table 2 Percentage distribution and the prevalence of depressive symptoms and housing conditions

\begin{tabular}{|c|c|c|c|c|}
\hline \multirow[b]{2}{*}{ Variable } & \multirow[b]{2}{*}{$\begin{array}{l}\text { Total } \\
\text { N (\%) }\end{array}$} & \multicolumn{2}{|c|}{ Depressive symptoms } & \multirow[b]{2}{*}{ P value } \\
\hline & & $\begin{array}{l}\text { Not depressed } \\
\text { n (\%) }\end{array}$ & $\begin{array}{l}\text { Depressed } \\
\text { n (\%) }\end{array}$ & \\
\hline \multicolumn{5}{|l|}{ Housing materials } \\
\hline Improved & $3567(77.80)$ & $1958(79.30)$ & $1609(76.04)$ & 0.008 \\
\hline Unimproved & $1018(22.20)$ & $511(20.70)$ & $507(23.96)$ & \\
\hline \multicolumn{5}{|l|}{ Cooking fuel } \\
\hline Polluting fuel & $2544(55.50)$ & $1287(52.13)$ & $1257(59.40)$ & \\
\hline Others & $48(1.05)$ & $26(1.05)$ & $22(1.04)$ & \\
\hline \multicolumn{5}{|l|}{ Type of toilet } \\
\hline Toilet with seat & $603(13.15)$ & $370(14.99)$ & $233(11.01)$ & $<0.001$ \\
\hline No & 1457 (31.78) & $740(29.97)$ & 717 (33.88) & \\
\hline \multicolumn{5}{|l|}{ Shower or bath facility } \\
\hline Yes & $1916(41.79)$ & $1128(45.69)$ & $788(37.24)$ & $<0.001$ \\
\hline No & 2669 (58.21) & 1341 (54.31) & 1328 (62.76) & \\
\hline
\end{tabular}

lead to poor access to mental health services, and further affect the diagnosis and treatment of depression, as it is very difficult for low-income populations to keep regular healthcare needs and be screened for depressive symptoms. ${ }^{8}$ How to approach these problems is outside the scope of this article, but our findings highlight the importance of SES on the development of depressive symptoms in rural China.

\section{Housing conditions and depression}

Poor housing conditions (using polluting cooking fuel, toilet without seat and having no bath facility) were found to be associated with depressive symptoms. Older individuals who used polluting cooking fuel was nearly 1.2 times more likely to have depression than those who used clean cooking fuel. Older individuals who used the toilet without seat and had no bath facility were almost 1.3 and 1.2 times more likely to have depression than those who used the toilet with seat and had a bath facility.

In this study, there are $2544(55.50 \%)$ older people using polluting cooking fuel in rural China in 2015. Indoor air pollution (IAP), one of the major public health concerns in low-income and middle-income countries, is caused mainly by the use of polluting cooking fuels, such as coal, charcoal, crop residue and wood burning. ${ }^{22} 23$ Globally, nearly 3 billion $(40 \%)$ of the world's population, according to a WHO report in 2016, relies on solid fuels, including coal and biomass for domestic cooking. Evidence shows that IAP is associated with poor physical health. ${ }^{24-27}$ Prior researchers have identified IAP as the most important environmental risk factor globally associated with adverse health effects ranging from respiratory infections to chronic illness, such as tuberculosis, chronic obstructive pulmonary disease and cancer. ${ }^{28-30}$ According to a HO report, almost 4.3 million deaths annually have been attributed to IAP globally, resulting from cooking fuel in low-income and middle-income countries in 2016. However, there is little empirical evidence on the relationship between IAP and psychological or mental health, such as anxiety and depression, based on nationally representative and longitudinal data, especially in low-income and middle-income countries. ${ }^{31-33}$ Generally speaking, the negative effects of polluting cooking fuel on depressive symptoms have not been given enough attention, especially in the older population, primarily because the effect of IAP on depression is largely dependent on the social vulnerability and mental resilience among different population groups.

Our study shows that 3982 older adults are still using the toilet without a seat in rural China, which accounted for $86.85 \%$. Very little research has explored the relationship between toilet type and depressive symptoms. Research on health, especially on microbiological pollution, has demonstrated that the species of microbes on squat pans are roughly the same as those on the toilet, while the numbers alone are much more. ${ }^{3435}$ As a result, the possibility of transmitting the virus through the air is greater. Some other previous investigations have suggested that using squat pans over time can cause anal fissure to a certain extent, raising the risk of dizziness due mainly to the lack of oxygen to the brain, which results from resuming blood circulation and flow to the lower limb artery after a long time using of squat pans, even leading to a fall or a cardiocerebral vascular accident, such as cerebral haemorrhage and angina pectoris, 


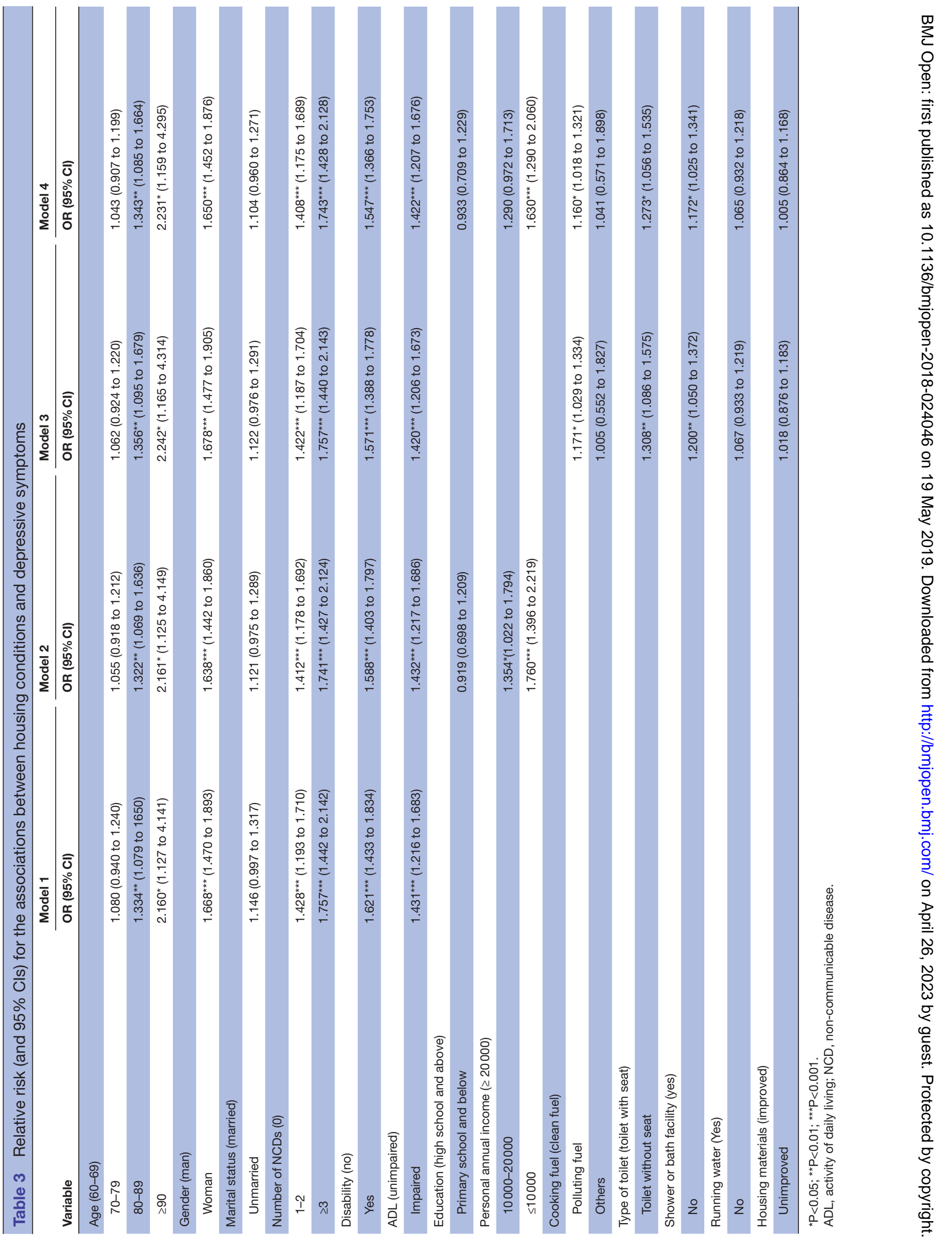


especially among patients with constipation. ${ }^{3637}$ Maybe we can deduce from these existing studies that the existence or deterioration of chronic diseases resulting from using the toilet without seat may lead to a greater possibility of depression among older adults, especially those with high blood pressure, heart disease, chronic bronchitis and other senile diseases.

Finally, in terms of the relationship between shower/ bath facility and depressive symptoms, there are 2669 $(58.21 \%)$ older adults who reported that the shower/bath facility is not available among respondents in 2015. We found few articles involving the relationship between the availability of bath facilities and health outcome. ${ }^{38}$ Our findings underscore the importance of the availability of bath facilities on depressive symptoms among the elderly in rural China.

\section{Limitations}

The main limitations of this study were a cross-sectional study design and its use of self-report data. This study cannot use the Geriatric Depression Scale to assess or screen for depression in the elderly according to original data. Finally, we used screening instruments of depression only while no diagnostic instrument was used to further confirm depression.

\section{CONCLUSIONS}

Using a large nationally representative sample of elderly in rural China, we concluded that the elderly in rural china experienced severe depressive symptoms. The study identified lowest personal annual income, polluting cooking fuel, toilet without seat and having no bath facility as being significantly associated with more depressive symptoms. Older adults living in rural areas are the vulnerable group that faces multiple serious health inequities. Therefore, this study emphasises that SES and housing conditions are important for this vulnerable group and should at least be part of the current governmental intervention to improve depressive symptoms. In addition, further studies should investigate the rural-urban differences among elderly adults using a prospective design.

Contributors XM conceived and designed the study. MF analysed and wrote the paper. GM and $L G$ were responsible for revising the work.

Funding We would like to acknowledge the China Health and Retirement Longitudinal Study team for providing data. In addition, the authors acknowledge support from China Medical Board: Public Health Education Reformation in China (04-804).

\section{Competing interests None declared.}

Patient consent for publication Not required.

Ethics approval The baseline data collection was obtained from the Biomedical Ethics Review Committee of Peking University (IRB00001052-11015). The use of China Health and Retirement Longitudinal Study data was obtained from the University of Newcastle's Human Research Ethics Committee (H-2015-0290).

Provenance and peer review Not commissioned; externally peer reviewed. Data sharing statement № additional data are available.

Open access This is an open access article distributed in accordance with the Creative Commons Attribution Non Commercial (CC BY-NC 4.0) license, which permits others to distribute, remix, adapt, build upon this work non-commercially, and license their derivative works on different terms, provided the original work is properly cited, appropriate credit is given, any changes made indicated, and the use is non-commercial. See: http://creativecommons.org/licenses/by-nc/4.0/.

\section{REFERENCES}

1. World report on ageing and health. World report on ageing and health. 2015 http://www.who.int/ageing/events/world-report-2015launch/en/ (Accessed 15th Jan 2018).

2. UNFPA and HelpAge International. Ageing in the twenty-first century: a celebration and a challenge. 2012 https://www.unfpa.org/ publications/ageing-twenty-first-century (Accessed 15th Jan 2018).

3. UNFPA. UNFPA and Helpage international ageing. https://www. unfpa.org/ageing (Accessed 15th Jan 2018).

4. Mental health. Mental health of older adults. http://www.who.int/ mediacentre/factsheets/fs381/en/ (Accessed 15th Jan 2018).

5. Gallo LC, Matthews KA. Understanding the association between socioeconomic status and physical health: do negative emotions play a role? Psychol Bull 2003;129:10-51.

6. Vonneilich $\mathrm{N}$, Jöckel $\mathrm{KH}$, Erbel $\mathrm{R}$, et al. The mediating effect of socia relationships on the association between socioeconomic status and subjective health - results from the Heinz Nixdorf Recall cohort study. BMC Public Health 2012;12:285.

7. Pappa E, Chatzikonstantinidou S, Chalkiopoulos G, et al. Healthrelated quality of life of the roma in greece: the role of socioeconomic characteristics and housing conditions. Int J Environ Res Public Health 2015;12:6669-81.

8. Ng CW, Tan WS, Gunapal PP, et al. Association of Socioeconomic Status (SES) and social support with depressive symptoms among the elderly in Singapore. Ann Acad Med Singapore 2014;43:576-87.

9. Lawrence R. Constancy and change: key issues in housing and health research, 1987-2017. Int J Environ Res Public Health 2017; $14: 763$.

10. Nguyen QC, Rehkopf DH, Schmidt NM, et al. Heterogeneous effects of housing vouchers on the mental health of us adolescents. Am J Public Health 2016;106:755-62.

11. Gibson M, Petticrew M, Bambra C, et al. Housing and health inequalities: a synthesis of systematic reviews of interventions aimed at different pathways linking housing and health. Health Place 2011:17:175-184.

12. Thomson H, Thomas S, Sellstrom E, et al. The health impacts of housing improvement: a systematic review of intervention studies from 1887 to 2007. Am J Public Health 2009;99:S681-92.

13. Suglia SF, Duarte CS, Sandel MT, et al. Housing quality, housing instability, and maternal mental health. J Urban Health 2011;88:1105-16.

14. Barton A, Basham M, Foy C, et al. The watcombe housing study: the short term effect of improving housing conditions on the health of residents. J Epidemiol Community Health 2007;61:771-7.

15. Hamoudi A, Dowd JB. Housing wealth, psychological well-being and cognitive functioning of older Americans. J Gerontol B Psychol Sci Soc Sci 2014;69:253-62.

16. de Wet T, Plagerson S, Harpham T, et al. Poor housing, good health: a comparison of formal and informal housing in Johannesburg, South Africa. Int J Public Health 2011;56:625-33.

17. Andersen MJ, Williamson AB, Fernando $P$, et al. Housing conditions of urban households with Aboriginal children in NSW Australia: tenure type matters. BMC Public Health 2018;18:70.

18. Li LW, Liu J, Zhang Z, et al. Late-life depression in Rural China: do village infrastructure and availability of community resources matter? Int J Geriatr Psychiatry 2015;30:729-36.

19. Cheng HG, Chen S, McBride O, et al. Prospective relationship of depressive symptoms, drinking, and tobacco smoking among middle-aged and elderly community-dwelling adults: results from the China Health and Retirement Longitudinal Study (CHARLS). J Affect Disord 2016;195:136-43.

20. Liu H, Xu X, Hall JJ, et al. Differences in depression between unknown diabetes and known diabetes: results from China health and retirement longitudinal study. Int Psychogeriatr 2016;28:1191-9.

21. Lei X, Sun X, Strauss J, et al. Depressive symptoms and SES among the mid-aged and elderly in China: evidence from the China Health and Retirement Longitudinal Study national baseline. Soc Sci Med 2014;120:224-32.

22. Naz S, Page A, Agho KE. Household air pollution from use of cooking fuel and under-five mortality: the role of breastfeeding status and kitchen location in Pakistan. PLoS One 2017;12:e0173256.

23. Hou B-D, Tang $X, M a C$, et al. Cooking fuel choice in rural China: results from microdata. J Clean Prod 2017;142:538-47. 
24. Owili PO, Muga MA, Pan WC, et al. Cooking fuel and risk of underfive mortality in 23 Sub-Saharan African countries: a populationbased study. Int J Environ Health Res 2017;27:191-204.

25. Xiaokang LV, Cong W. Exposure to Air pollution impairs cognitive function and psychological well-being. J. Advances in Psychological Science 2017;25:111-20.

26. Asikainen A, Carrer P, Kephalopoulos S, et al. Reducing burden of disease from residential indoor air exposures in Europe (HEALTHVENT project). Environmental Health 2016;15:S35.

27. Pollard SL, Williams DL, Breysse PN, et al. A cross-sectional study of determinants of indoor environmental exposures in households with and without chronic exposure to biomass fuel smoke. Environ Health 2014;13:21.

28. Bates MN, Chandyo RK, Valentiner-Branth P, et al. Acute lower respiratory infection in childhood and household fuel use in Bhaktapur, Nepal. Environ Health Perspect 2013;121:637-42.

29. Painschab MS, Davila-Roman VG, Gilman RH, et al. Chronic exposure to biomass fuel is associated with increased carotid artery intima-media thickness and a higher prevalence of atherosclerotic plaque. Heart 2013;99:984-91.

30. Fatmi Z, Coggon D. Coronary heart disease and household air pollution from use of solid fuel: a systematic review. Br Med Bull 2016;118:91-109.

31. Agrawal S. Effect of indoor air pollution from biomass and solid fuel combustion on prevalence of self-reported asthma among adult men and women in India: findings from a nationwide large-scale crosssectional survey. J Asthma 2012;49:355-65.

32. Nie P, Sousa-Poza A, Xue J. Fuel for life: domestic cooking fuels and women's health in rural China. Int J Environ Res Public Health 2016;13:E810.

33. Khan MN, B Nurs CZ, Mofizul Islam M, et al. Household air pollution from cooking and risk of adverse health and birth outcomes in Bangladesh: a nationwide population-based study. Environ Health 2017; $16: 57$.

34. Li Chengle LY, Yi Y, Li Yue XW. Evaluation of squat pan and toilet in sanitation, health and water-saving. Inner Mongolia Environmental Sciences 2017;4:243-4.

35. Sinclair RG, Gerba CP. Microbial contamination in kitchens and bathrooms of rural Cambodian village households. Lett Appl Microbiol 2011;52:144-9.

36. Mohammadjavad D, Mohammadreza D, et al. Role of toilet type in transmission of infections. J. Academic Research International 2011;2:110-3.

37. Erel S, Adahan D, Kismet K, et al. Risk factors special to eastern culture for the development of anal fissure. Bratis/ Lek Listy 2009;110:710-2.

38. Horne JA, Shackell BS. Slow wave sleep elevations after body heating: proximity to sleep and effects of aspirin. Sleep 1987;10:383-92. 